Профилактика. Самое главное в профилактике, это избегание некачественной консервной продукции.

Лечение. Единственное лечение - это срочное, внутривенно - струйное введение (рискуя развитием анафилактического шока) противоботулинической сыворотки или анатоксина. Сначала вводят $15000 \mathrm{ME}$, при отсутствии положительной динамики - повторное введение через 5 часов 5000 МЕ. При употреблении подозрительного продукта, рекомендуется в целях профилактики введение сыворотки в дозе 2000 ME.

$* * *$

1. Лобзин Ю.В. Руководство по инфекционным болезням.// Санкт Петербург. Фолиат. 2000Г

2. Бактериальные пищевые отравления.// Москва М.Д. Крылова.2001г.

3. Инфекционные болезни и эпидемиология.// учебник для ВУЗов издательство ГЭОТАР.2000г. Покровский В.И., С.Г.Пак, Н.И. Брико, Б.К. Данилкин.

\title{
Dylenok A.A. \\ The state of diagnosis of "early" stomach cancer in the Yaroslavl region
}

doi: $10.18411 / \mathrm{sr}-10-04-2021-10$

Relevance. According to the data of the International Agency for Research on Cancer, 181,000 (18\%) of 1.03 million cases of gastric cancer identified in 2018 were cardiac or proximal gastric cancers, while $853,000(82 \%)$ cases were non-cardiac or distal gastric cancers, which shows a clear predominance of distal localities. Gender also has its own characteristics in relation to this disease; this is reflected in the fact that two-thirds of all the detected cases of gastric carcinoma in the world account for the male population, and this proportion was higher for cardiac cancer: according to estimates, three-quarters of all patients were men $[1,2]$.

The distribution of this disease among the world's population is equally heterogeneous. The main burden of gastric cancer is borne by the countries of Southeast Asia (Japan, South Korea, China), where the incidence rate of distal localization is at the level of 17.9 per 100,000 population. In contrast, in North America, the level of this indicator is 2.8.

The uneven incidence of gastric cancer around the world is clearly visible while assessing this indicator in the United States of America and Canada, as the largest and most populated countries in the Western hemisphere. The most common types of cancer in North America that were expected to be diagnosed in men in 2020 are: prostate, lung and bronchial cancer, and rectal cancer that account for $43 \%$ of all cases in men, with prostate cancer alone accounting for more than 1 in 5 new diagnoses.

In Russian scholarly literature, the issue of early gastric cancer diagnosis has been covered since the beginning of the 2000s. Already the first publications expressed concern about the low level of detection of this category of patients, since during this period of development of Russia, 75\% of cases of gastric cancer were diagnosed in stages III-IV of the disease. Over the past two decades, there has been an increase in Russian publications on this topic. No separate epidemiological studies on gastric cancer have been identified, but the regularly updated publication edited by Kaprin makes it possible to assess the positive dynamics that have formed in Russia over the past 10 years. In relation to gastric cancer, the proportion of stages I-II among all cases detected in 2009 was only $24.6 \%$, and in 2019 it equaled $37.1 \%$. Also, a positive trend is observed in the one-year case-fatality rate that has been steadily reducing over the last 10 years - from 53.2\% in 2009 to $45.8 \%$ in 2019. There are no separate statistics on the specific gravity of intraepithelial gastric cancer (T1aNoMo and T1bNoMo) [3-6]. 
Purpose of the research. Determination of the specific gravity of the so-called "early" gastric cancer in relation to the incidence rate of stomach cancer in the Yaroslavl Region.

Materials and methods. According to the aim of determining the specific gravity of earlier forms of gastric cancer in the structure of this nosology, the author performed a retrospective analysis of cases of patients who had undergone special treatment (diagnosis gastric cancer) at the Yaroslavl Regional Oncology Clinical Hospital during the period from 2009 to 2019. The subject of the research was the following medical documentation: outpatient's card (form 025/u-004), inpatient's card (form 003/u), protocols of endoscopic examination (Order of the Ministry of Health of the Russian Federation No. 974n dated December 6, 2017), the protocol of antemortem pathology study of the operating material (form No. 014-1/u).

Results. Thus, the medical records of 965 patients with an established diagnosis of gastric cancer were analyzed. Among this group of patients, there were 448 women $(46.4 \%)$, 517 men (53.6\%), the average age equaled $64.2 \pm 10.2$ years, with a minimum age of 28 years, and a maximum of 87 years.

Table 1

Distribution of patients by age

\begin{tabular}{|l|l|}
\hline Age group & Number of patients \\
\hline $18-44$ years old & 33 \\
\hline $45-59$ years old & 259 \\
\hline $60-74$ years old & 517 \\
\hline $75-90$ years old & 156 \\
\hline$>90$ years old & - \\
\hline
\end{tabular}

All the patients were examined before treatment in accordance with the clinical recommendations and treatment standards of the Ministry of Health of the Russian Federation. In order to stage the tumor process, the classification of malignant tumors (TNM, 7 revision (2009)), developed and first published in 1968 by the Union for International Cancer Control (UICC), was used [52]. Taking into account the stage of the tumor process, the presence of concomitant pathology, and the degree of its compensation, the author organized a multi-disciplinary discussion; an oncologist-surgeon, an oncologist-radiologist, an oncologist-chemotherapist, and a pathologist took part in it in order to develop a rational treatment strategy for patients.

For the purpose of confirming the diagnosis of "early" [7, 8] gastric cancer, all the morphological micro-preparations prepared from surgical material were retrospectively reviewed by a pathologist (highest qualification category in the specialty "Pathomorphology") who completed an internship at the pathoanatomical departments of cancer centers in Japan and Germany (Klinikum Bayreuth Institute for Pathology, Germany; Faculty of Medicine at Fukuoka University, Japan). As a result of all the conducted work, patients with neuroendocrine malignant gastric tumors, multicentric gastric cancers, as well as patients with previously undergone combined and complex special treatment for malignant tumors of other localizations were eliminated from the group of patients with a diagnosis of stage I gastric cancer established at the preoperative stage.

All the patients participating in the research were included in the generated original database "Database of patients with gastric cancer indicating the statistics of patients with certain types of surgical intervention, treated at the Yaroslavl Regional State Budgetary Healthcare Institution "Oncology Clinical Hospital" for the period from 2009 to 2019".

Conclusions. The detection rate of "early" gastric cancer forms in the Yaroslavl Region is at a level that has been steadily increasing over the past ten years. In order to improve the results of treatment of this nosology, it is necessary to introduce screening programs that will increase the proportion of detected early forms of gastric cancer. It is 
necessary to keep separate records of the pT1a and pT1b stages, as there are differences in approaches and treatment results.

$$
* * *
$$

1. Arnold, M., Park, J.Y., Camargo, M.C., Lunet, N., Forman, D., \& Soerjomataram, I. (2020). Is Gastric Cancer Becoming a Rare Disease? A Global Assessment of Predicted Incidence Trends to 2035. Gut, 69(5), 823-829.

2. Human Development Indices and Indicators - 2018 Statistical Update. (2018). New York: United Nations Development Programme.

3. Kaprin, A.D., Starinsky, V.V., \& Petrova, G.B. (2018). Malignant Neoplasms in Russia in 2017 (Incidence and Mortality). Moscow: Herzen Moscow State Medical Research Institute - Branch of the Federal State Budgetary Institution "NMIC of Radiology" of the Ministry of Health of Russia.

4. Kaprin, A.D., Starinsky, V.V., \& Petrova, G.B. (2019). Malignant Neoplasms in Russia in 2018 (Incidence and Mortality). Moscow: Herzen Moscow State Medical Research Institute - Branch of the Federal State Budgetary Institution "NMIC of Radiology" of the Ministry of Health of Russia.

5. Kaprin, A.D., Starinsky, V.V., \& Petrova, G.B. (2018). Malignant Neoplasms in Russia in 2016 (Incidence and Mortality). Moscow: Herzen Moscow State Medical Research Institute - Branch of the Federal State Budgetary Institution "NMIC of Radiology" of the Ministry of Health of Russia.

6. Kaprin, A.D., Starinsky, V.V., \& Petrova, G.B. (2017). Malignant Neoplasms in Russia in 2015 (Incidence and Mortality). Moscow: Herzen Moscow State Medical Research Institute - Branch of the Federal State Budgetary Institution "NMIC of Radiology" of the Ministry of Health of Russia.

7. Ono, H., Kondo, H., Gotoda, T., Shirao, K., Yamaguchi, H., Saito, D., Hosokawa, K., Shimoda, T., \& Yoshida, S. (2001). Endoscopic Mucosal Resection for Treatment of Early Gastric Cancer. Gut, 48(2), 225-229.

8. Besova, N.S., Byakhov, M.Y., Gorbunova, V.A. et al. (2014). Clinical Recommendations for the Diagnosis and Treatment of Patients with Gastric Cancer. Moscow: Association of Oncologists of Russia.

\section{Yatsenko L.A., Dzen N.V., Gabbasova N.V., Mamchik N.P. The adaptive potential of workers in greenhouse farms in the Voronezh region}

Voronezh State Medical University named after N.N. Burdenko (Voronezh, Russia)

doi: $10.18411 / s r-10-04-2021-11$

\section{Abstract}

Adaptive potential is an indicator of the level of adaptability of the human body to various and changing environmental factors. The adaptive capabilities of the body are influenced not only by external factors, but also by internal - the state of the body as a whole, by the presence or absence of chronic diseases. Therefore, the adaptive potential was used as an integral indicator of a person's adaptability to production factors. The aim of the study was to assess the adaptive capabilities of the organism of workers in greenhouse farms in the Voronezh region. The study was carried out at the enterprises of the closed ground of the region by the method of questioning, the objects of the study were 125 women aged 27-45 years. In most cases, there are violations of the adaptive capabilities of the organism among the studied workers of greenhouse farms, and even a breakdown in adaptation was revealed in $0.8 \%$. In less than half of the cases, the adaptive potential of the greenhouses was within the normal. The adaptive reserves of the greenhouses workers decrease with age.

Keywords: greenhouse workers, lifestyle, primary risk factors, adaptive potential.

The socio-economic and socio-political well-being of the country is determined by the health of the working-age population. The priority task of each state is to preserve and strengthen the health of the population $[1,2]$. The main production factors affecting a working person are "triggers" for the formation of occupational pathology and the occurrence of neuroemotional overload. The health level also depends on individual adaptive capabilities. [3]. Adaptive potential is an indicator of the level of adaptability of the human body to various and changing environmental factors. The adaptive capabilities of the body are influenced not 